\title{
Temperature Control of Heating Zone for Drying Process: Effect of Air Velocity Change
}

\author{
Chananchai Wutthithanyawat ${ }^{1, a}$ and Nawadee Srisiriwat ${ }^{2}$ \\ ${ }^{1}$ Department of Instrumentation and Control Engineering, Pathumwan Institute of Technology, Bangkok 10330, Thailand \\ ${ }^{2}$ Department of Petrochemicals and Environmental Management, Pathumwan Institute of Technology, Bangkok 10330, Thailand
}

\begin{abstract}
This paper proposes a temperature control technique to adjust air temperature in a heating zone for drying process. The controller design is achieved by using an internal model control (IMC) approach. When the IMC controller parameters were designed by calculating from an actual process transfer function estimated through an open-loop step response with input step change from $50 \%$ to $60 \%$ at a reference condition at air velocity of $1.20 \mathrm{~m} / \mathrm{s}$, the performance of temperature controller was experimentally tested by varying an air velocity between $1.32 \mathrm{~m} / \mathrm{s}$ and $1.57 \mathrm{~m} / \mathrm{s}$, respectively. The experimental results showed that IMC controller had a high competency for controlling the drying temperature.
\end{abstract}

\section{Introduction}

Drying process is widely used for food processing to preserve foods by removing enough moisture from foods to prevent food spoilage in which effective drying depends on: adequate heat to draw out moisture, without cooking the food; dry air to absorb the released moisture; and enough air circulation to remove the moisture [1]. Air flow rate and temperature in drying chamber affect the moisture removal rate from foods [2]. Consequently, the air flow rate and temperature control is very important to generate hot air in heating zone of food drying process.

In our previous work [3], the temperature distribution of hot air flow in heating zone of a rectangular duct was investigated by varying the power supply to a coil heater and an electrical fan in order to generate hot air entering the drying chamber that is crucial to control the desired temperature and keep the quality of air for drying process. This experiment installation associated with a data acquisition (DAQ) card and a computer was also conducted to generate user interfaces on the computer by using LabVIEW [4].

Currently, there are many control techniques used for the food drying system such as herb [5], gain [6], codfish [7-8], and fruit [9]. Nafeh et al. [5] investigated a temperature control in a PV-Wind medical herb dryer system by using on/off controller that showed the high capability of the proposed technique in controlling the drying temperature. Han et al. [6] used a model predictive control (MPC) system based on neural network which was designed and tested on two model corn dryers that the control method of the system can be used in drying process control. Boeri et al. experimentally investigated the optimized operating drying control for temperature,

\footnotetext{
a Corresponding author: chananchai.wut@pit.ac.th
}

relative humidity and air velocity parameters by using fuzzy logic approach [7] and also proposed the multiinput-multi-output-based PID and Fuzzy logic (FLC) controller for a drying control process [8]. Geddes [9] implemented an internal model control (IMC) model to the temperature controller for fruit dryer process in which the simulation results showed that IMC controlled system could achieve the requirement of providing offset-free responses at steady state. Although there are many works concerning a controller design for the food drying process, the research relating to the experimental installation and controller design using IMC for the drying system is limited.

In this paper, the drying temperature controller was designed by using IMC to adjust the desired temperature by manipulating the power supply of coil heater used for heating air in the heating zone of drying process. Because the foods are sensitive to heat, there is a suitable drying temperature for each food and the air flow rate is another important parameter varied to remove moisture to be the required value at the fixed temperature. Consequently, the temperature response with varying air velocity was investigated and the capability for temperature controlling was experimentally tested.

\section{Experimental Installation}

In the heating zone, the main apparatuses are composed of a $500 \mathrm{~W}$ coil heater, supplied with the input signal in the range of 0 to $+5 \mathrm{VDC}$ to generate the maximum temperature about $102.8^{\circ} \mathrm{C}$, and an electrical fan (EBMPAPST, 8414N/2GH), adjusted the input signal in the range of 0 to +5 VDC to provide variable air velocity between 1.20 and $1.57 \mathrm{~m} / \mathrm{s}$ corresponding to the air 
flowrate from 0.87 to $1.14 \mathrm{~m}^{3} / \mathrm{min}$. The atmospheric air forced by electrical fan flows across the coil heater to generate hot air passing through the non-insulated rectangular duct as shown in Fig. 1. The air velocity was measured by using a Panasonic SUNX Photo Sensor PMK44. The temperatures inside the rectangular duct at various positions were measured by RTD (resistance temperature detector). The bottom of apparatus is the circuits of measurement and control system and the output terminal can be used to send the signal and then monitor the temperature of three positions in rectangular duct and the air velocity via LabVIEW [4].

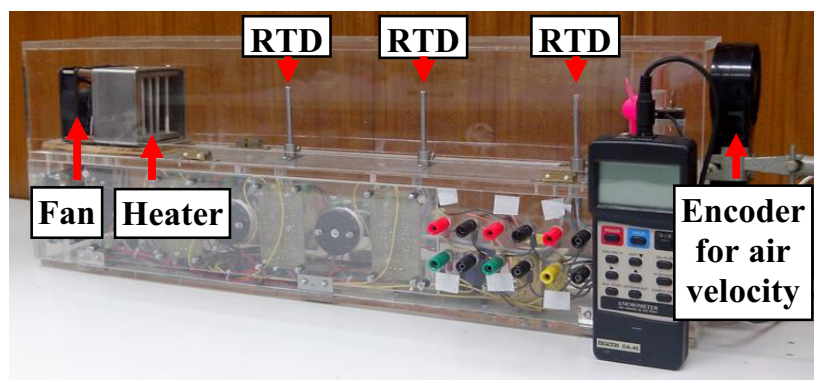

Figure 1. Experimental apparatus [3].

\section{Design of Temperature Control}

It is known from the previous discussion that the main function of the electrical heater is to supply the heating required by the drying air. The block diagram of thermal process based on two-input single-output (TISO) system is illustrated in Fig. 2 which includes the temperature control system and the air velocity control system.

When the open-loop system was provided with a step input, the process step testing was carried out to characterize three parameters, the gain $K$, the dead time $t_{0}$ and the time constants $\tau$, for determining the first-order plus dead-time (FOPDT) model. Accordingly, the combination of the transfer functions, $G_{P}(s)$, is approximated by FOPDT model for the purpose of characterizing the dynamic response of the process. In this step testing, to obtain the maximum gain value, the change of $10 \%$ of step input from 0 to $90 \%$ was tested for RTD\#1 and it was found that at a step change, started at $100 \mathrm{sec}$, from $50 \%$ to $60 \%$ gave the highest value of steady-state gain in which the process variable was changed from $49.62 \%$ to $65.13 \%$ or from $62.21^{\circ} \mathrm{C}$ to $73.85^{\circ} \mathrm{C}$ for the step change in controller output of magnitude is $0.5 \mathrm{~V}$. Therefore, the steady-state gain of process, $K$, can be calculated as $23.27^{\circ} \mathrm{C} / \mathrm{V}$ corresponding to $1.47 \% / \%$. Using Fit 1 method to determine the dead time and time constant [10], the values of $t_{0}$ and $\tau$ are approximately $15 \mathrm{sec}$ and $150 \mathrm{sec}$, respectively. Thus, the resulting FOPDT model transfer function of actual process, $G_{P}(s)$, is shown in Eq. (1).

$$
G_{P}(s)=\frac{K e^{-t_{0} s}}{\tau s+1}=\frac{1.47 e^{-15 s}}{150 s+1}
$$

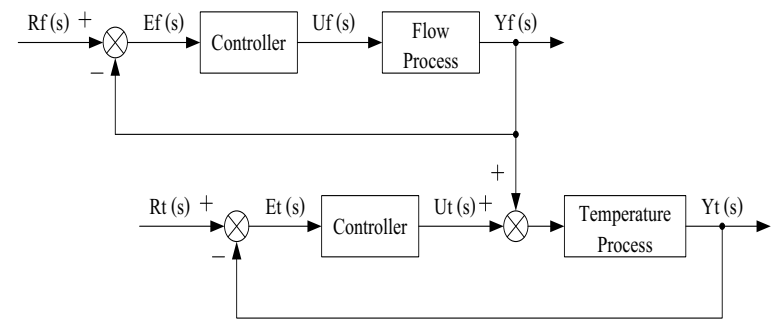

Figure 2. TISO Block diagram of the temperature control system coordinated air flow control system.

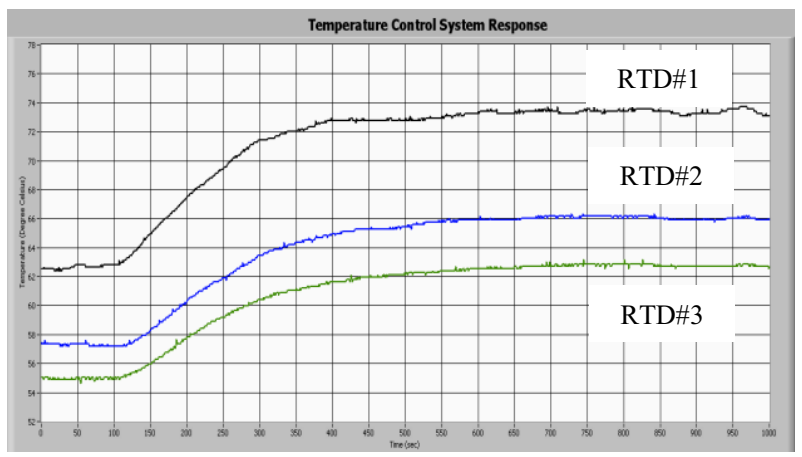

Figure 3. Open-loop step response of temperature process from $50 \%$ to $60 \%$.

In process control applications, model based control systems are often used to track set points and reject low disturbances. Particularly, if the control structure has been developed based on the exact model of the process then perfect control is theoretically possible. For controller design in this paper, IMC based PI (proportional integral) design procedure for a first order system was applied to control air temperature at the RTD\#1 position and the fixed air velocity of $1.20 \mathrm{~m} / \mathrm{s}$. The PI tuning parameters of controller were calculated by Eq. (2) [11]. Hence, the tuning parameters of $K_{c}$ and $T_{i}$ are 1.13 and $150 \mathrm{sec}$, respectively.

$$
K_{C}=\frac{T}{K\left(T_{f}+t_{0}\right)} ; T_{i}=T
$$

where $K_{c}$ is controller gain [\%/\%], $K$ process gain [\%/\%], $T_{i}$ integral time constant [sec], $T_{f}$ filter time constant [sec], $t_{0}$ dead time [sec] and $T$ is process time constant [sec]. In this paper, as a rule of thumb $T_{f}$ is $75 \mathrm{sec}$ chosen to be at least twice as fast as the time constant from open-loop response of process [9].

\section{Results and Discussion}

The aim of the temperature control system is to adjust the temperature in heating zone of drying chamber at which the range of temperature and air velocity varying in this study was generally used in the drying foods. After the IMC controller parameters were designed, to investigate the performance of the proposed temperature control system, the response of the drying temperature was tested at different air velocities between 1.32 and $1.57 \mathrm{~m} / \mathrm{s}$ 
corresponding to the step change of input signal from 20 to $100 \%$ of +5 VDC for supplying the electric fan.

Figs. 4(a) and 4(b) illustrate the temperature response and the control signal, respectively, in case of using IMC controller. In this test, a set point of drying temperature was nearly $62.52^{\circ} \mathrm{C}$ which is at $50 \%$ operating point of temperature control system. The change of air velocity entering the heating zone in drying chamber was assumed as a disturbance of drying process. As shown in Fig. 4, the step changes of input signal of the electric fan at 20 , $40,60,80$ and $100 \%$, representing the air velocity at 1.32 , $1.41,1.49,1.55$ and $1.57 \mathrm{~m} / \mathrm{s}$, respectively, were started at $100 \mathrm{sec}$. An ambient temperature was about $25^{\circ} \mathrm{C}$.

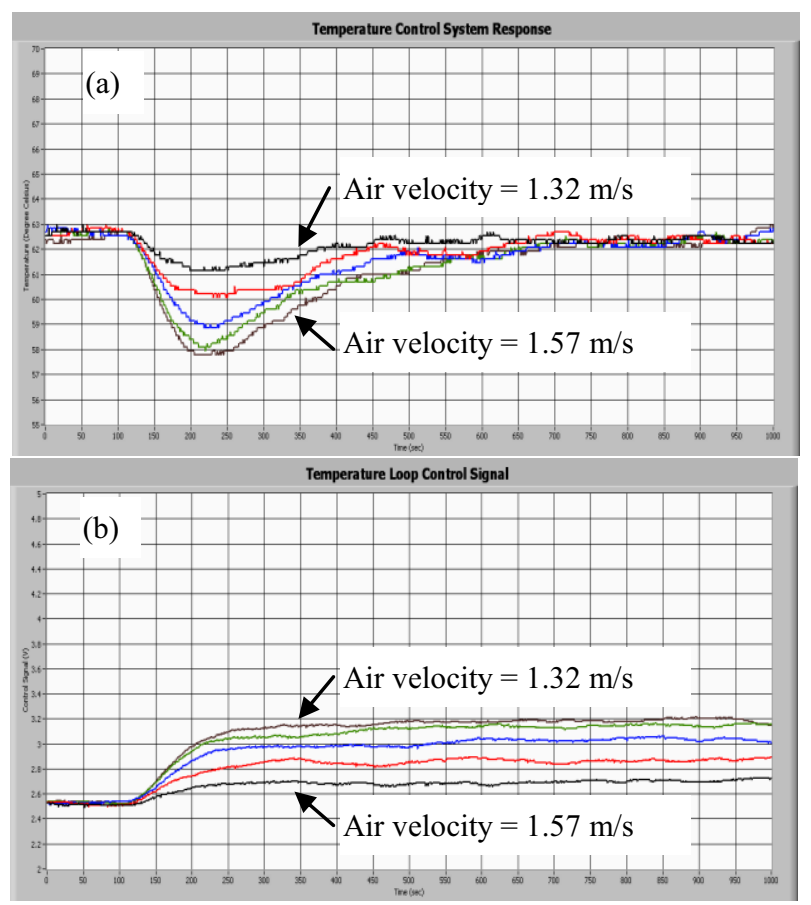

Figure 4. Effects of air velocity on (a) temperature control system response; $\mathrm{x}$-axis is time [sec] and $\mathrm{y}$-axis is temperature $\left[{ }^{\circ} \mathrm{C}\right]$ and (b) temperature loop control signal; $\mathrm{x}$-axis is time [sec] and $\mathrm{y}$-axis is control signal [V].

At step change of $20 \%$, when the air velocity was changed from $1.20 \mathrm{~m} / \mathrm{s}$ to $1.32 \mathrm{~m} / \mathrm{s}$, the minimum temperature was about $61.14^{\circ} \mathrm{C}$ (about $48.0 \%$ ) which decreases to $2.0 \%$ from the set point and the control system took a settling time of $350 \mathrm{sec}$ to come within the prescribed value and remain within the acceptably value as shown in Fig. 4(a). The control signal was about 54\% which is more than $50 \%$ of a reference operating condition, that is, the control signal increased $4 \%$ as illustrated in Fig. 4(b). If the inlet air velocity increases, thus making a disturbance, its effect must propagate through the entire heating zone before the drying temperature changes. Once the required value of drying temperature changes, the signal from the controller also changes. An increase of air velocity decreased the minimum temperature response. At $100 \%$ step change of air velocity, the minimum temperature was at $57.85^{\circ} \mathrm{C}$ or about $43.8 \%$ which decreased to $6.2 \%$ from set point that the control signal was about $64 \%$. The settling time increased with increasing the air velocity to reach the set point of drying temperature and moreover, the increase of air velocity in range of 60 to $100 \%$ used the highest settling time about $600 \mathrm{sec}$. Although the temperature control system took a long time to control the desired drying temperature because this is the worst case of a non-insulated system in order to test an ability of control system, the drying temperature was efficiently controlled nearly set point. Consequently, it can be concluded that the control of drying temperature was achieved through using IMC controller which gave a high capability.

\section{Conclusion}

The temperature control system of heating zone in drying chamber was performed by using internal control model (IMC). The drying temperature and air velocity in range of testing in this paper are usually applied in food drying process. The IMC based PI control was designed to adjust the drying temperature at the required value at approximately $62.52^{\circ} \mathrm{C}(50 \%$ operating condition $)$ at 1.20 $\mathrm{m} / \mathrm{s}$ of air velocity to control the operation of the electric heater. To investigate an efficiency of control system, the air velocity, assumed as a disturbance, was varied between 1.32 and $1.57 \mathrm{~m} / \mathrm{s}$. The experimental results indicated that the proposed IMC based PI controller gave a good capability in controlling the drying temperature.

\section{References}

1. P. Kendall, P. DiPersio, J. Sofos, Food and Nutrition Series/Preparation 9.308, (2012)

2. M.A. Tabassum, V.K. Jindal, Pakistan Journal of Agricultural Research 13, 312-319 (1992)

3. C. Wutthithanyawat, N. Srisiriwat, Applied Mechanics and Materials 627, 153-157 (2014)

4. C. Wutthithanyawat, N. Srisiriwat, Applied Mechanics and Materials 619, 303-308 (2014)

5. A. Shafy, A. Nafeh, E.A. Sweelem, F.H. Fahmy, Smart Grid and Renewable Energy 4, 153-160 (2013)

6. F. Han, C. Zuo, W. Wu, J. Li, Z. Liu, Mathematical Problems in Engineering Article ID 584376, (2012)

7. C. Boeri, F. Neto da Silva, J. Ferreira, M. Soares dos Santos, European Drying Conference EuroDrying'2011, Spain, (2011)

8. C.N. Boeri, F.N. da Silva, J. Ferreira, Acta Scientiarum. Technology 35, 279-289 (2013)

9. S.A. Geddes, Internal Model Control (IMC) of a Fruit Drying System, Bachelor of Engineering dissertation, Faculty of Engineering and Surveying, University of Southern Queensland, (2006)

10. C.A. Smith, A.B. Corripio, Principles and Practice of Automatic Process Control, John Wiley \& Sons, Inc., Canada, (1985)

11. R. Singh, R. Bala, B. Bhatia, International Journal of Advanced Research in Computer Science and Software Engineering 4, 915-922 (2014) 